\title{
The clinical significance of routine risk categorization in metastatic renal cell carcinoma and its impact on treatment decision-making: a systematic review
}

\author{
Shouki Bazarbashi*,1(D), Abdullah Alsharm², Faisal Azam³, Hazem El Ashry ${ }^{\text {(D) } \& \text { Jamal }}$ \\ Zekri ${ }^{5,6}$ \\ ${ }^{1}$ Department of Medical Oncology, King Faisal Specialist Hospital \& Research Center, Riyadh, Faculty of Medicine, Alfaisal \\ University, Riyadh, 12713, Saudi Arabia \\ 2Department of Medical Oncology, King Fahad Medical City, Riyadh, 12231, Saudi Arabia \\ ${ }^{3}$ Department of Medical Oncology, King Fahad Specialist Hospital, Dammam, 32253, Saudi Arabia \\ ${ }^{4}$ Department of Medical Affairs, Pfizer Ltd, Jeddah, 21391, Saudi Arabia \\ ${ }^{5}$ Department of Medical Oncology, King Faisal Specialist Hospital \& Research Center, Jeddah, Saudi Arabia \\ ${ }^{6}$ College of Medicine, Al-Faisal University, Riyadh, 11533, Saudi Arabia \\ *Author for correspondence: Tel.: +966 14647272 Ext.: 82115; bazarbashi@gmail.com
}

Aim: To analyze responses to first-line metastatic renal cell carcinoma (mRCC) treatment stratified by risk criteria. Patients \& methods: Clinical trials and observational studies of patients aged $\geq 18$ years, published January 2005-May 2019, were identified via Ovid from MEDLINE, EMBASE, the Cochrane Central Trials Register and the Cochrane Database of Systematic Reviews. Data extracted included progressionfree survival (PFS), overall survival (OS) and objective response rate (ORR). Results: 47/1269 articles met eligibility criteria. Most studies stratified patients by International Metastatic RCC Database Consortium $(n=19)$ or Memorial Sloan Kettering Cancer Center $(n=21)$. PFS, OS and ORR varied according to risk group. Conclusion: Pembrolizumab + axitinib, ipilimumab + nivolumab and avelumab + axitinib were most effective across all risk groups. Favorable-risk patients benefit from sunitinib treatment.

First draft submitted: 18 May 2020; Accepted for publication: 3 August 2020; Published online: 1 September 2020

Keywords: combination treatment $\bullet$ guidelines $\bullet$ prognostic $\bullet$ renal cell carcinoma $\bullet$ risk group $\bullet$ sunitinib

Globally, there are an estimated 400,000 new cases of kidney cancer each year [1]. Renal cell carcinoma (RCC) represents almost $90 \%$ of new diagnoses, with approximately $20 \%$ of patients presenting with metastatic disease [2]. Within 5 years, depending on the stage and risk factors, $20 \%$ of patients with nonmetastatic RCC will have recurrence [2].

For the past decade, the VEGF-targeted tyrosine kinase inhibitor (TKI) sunitinib [3], has been the standard of care for first-line treatment of metastatic RCC (mRCC). Other available therapies that predominantly target the VEGF pathway include sorafenib, pazopanib, axitinib, cabozantinib, tivozanib (EU only), lenvatinib and bevacizumab. Everolimus and temsirolimus are also available for the treatment of mRCC, but largely target the mammalian target of rapamycin (mTOR). The approval of the immune checkpoint inhibitor combination nivolumab plus ipilimumab, and immune checkpoint-TKI combinations avelumab plus axitinib and pembrolizumab plus axitinib, represents the beginning of a dramatic shift in the standard of care for mRCC. In three pivotal Phase III studies, all three combinations reported improved progression-free survival (PFS) and objective response rate (ORR) when compared with sunitinib [4-6].

To aid clinical decision-making, RCC treatment guidelines have been updated and recommend first-line mRCC treatment be selected according to patient risk status $[7,8]$. The two most common prognostic models used to stratify patients with mRCC are the International Metastatic RCC Database Consortium (IMDC) model and the Memorial Sloan Kettering Cancer Center (MSKCC) model, which stratify patients into favorable (0 risk factors), intermediate (1-2 risk factors) or poor ( $\geq 3$ risk factors) risk groups. Risk factors common to both models include Karnofsky performance status (KPS), time from diagnosis to treatment, hemoglobin concentration and corrected 
Table 1. Eligibility criteria according to the PICOS framework.

\begin{tabular}{|c|c|}
\hline Population & $\begin{array}{l}\text { - Advanced/metastatic RCC } \\
\text { - Clear cell or sarcomatoid histology } \\
\text { - Aged } \geq 18 \text { years } \\
\text { - First-line treatment } \\
\text { - } 1 \text { January 2005-3 May } 2019\end{array}$ \\
\hline Intervention/comparator & $\begin{array}{l}\text { - Monotherapies: sunitinib, sorafenib, pazopanib, cabozantinib, axitinib, tivozanib, temsirolimus, nivolumab, ipilimumab, } \\
\text { bevacizumab, IFN- } \alpha \text {, atezolizumab, pembrolizumab, avelumab, IL-2, high dose IL-2 } \\
\text { - Combination therapies: nivolumab plus ipilimumab, bevacizumab plus IFN- } \alpha \text {, atezolizumab plus bevacizumab, pembrolizumab plus } \\
\text { axitinib, avelumab plus axitinib } \\
\text { - Other: Any pharmaceutical intervention(s) undergoing Phase III investigation as monotherapy or combination therapy }\end{array}$ \\
\hline Outcomes & - OS, PFS, ORR, PD, CR, SD, CBR, DOR, HRQoL \\
\hline Study design & $\begin{array}{l}\text { - Randomized clinical trials } \\
\text { - Nonrandomized clinical trials } \\
\text { - Observational studies }\end{array}$ \\
\hline
\end{tabular}

calcium concentration. The IMDC model includes the additional risk factors neutrophil and platelet counts and the MSKCC model includes lactate dehydrogenase concentration. Patients' outcomes are known to vary according to patient risk. In a large global expanded-access trial of over 4000 patients, OS was strongly associated with IMDC risk groups; median OS was 45.4, 18.9 and 6.2 months for patients of favorable, intermediate and poor risk, respectively [9]. Additionally, patients with $\geq 4$ IMDC or MSKCC risk factors may have substantially reduced survival [10].

This analysis aimed to identify and summarize the survival and response outcomes of current first-line treatments for patients with mRCC, stratified by prognostic risk criteria. Several studies have reported the efficacy of mRCC treatments in patients with differing risk profiles; however, there is a lack of collective evidence in support of treatment selection by risk categories across different risk models. This review compiles the published evidence and adds to current literature on the role of risk models in informed treatment selection.

\section{Methods}

\section{Search strategy \& selection criteria}

This systematic review was conducted based on Cochrane's dual review methodology [11] and the study protocol developed according to the Preferred Reporting Items for Systematic Reviews and Meta-Analyses Protocol (PRISMA-P) [12]. The Population, Interventions, Comparator, Outcomes and Study Designs (PICOS) framework informed eligibility criteria, which are summarized in Table 1. Eligible studies were identified via the Ovid platform from MEDLINE, EMBASE, the Cochrane Central Trials Register and the Cochrane Database of Systematic Reviews. The literature search was completed on 3 May 2019 and was limited to studies published between 1 January 2005 and 3 May 2019. Non-English language publications were excluded and are unlikely to impact systematic bias [13].

Clinical trials were identified using the filters recommended by the Scottish Intercollegiate Guidelines Network (SIGN) for MEDLINE and EMBASE [14]. Interventions were identified using terms for the generic names. Conference proceedings of the American Society of Clinical Oncology (ASCO) annual meeting, ASCO Genitourinary Cancers Symposium, European Society for Medical Oncology (ESMO) and World Nephrology Congress were performed manually for the years 2017 and 2018 via Ovid. The full electronic search strategy is reported in the Supplementary data (Supplementary Table 1). Reference lists from relevant reviews and publications selected for inclusion in this systematic literature review were searched manually to identify any publications that may not have been identified via a search of the databases.

\section{Data extraction \& outcomes}

Duplicate publications were removed from the combined database searches and the remaining references screened by title and abstract by two independent reviewers according to the eligibility criteria. Disagreements were reconciled by discussion and a third reviewer was included for consensus for unresolved discrepancies. Following initial screening, the two reviewers reviewed the full text of the selected publications to confirm eligibility. A similar approach was employed for data extraction; two independent reviewers extracted the relevant data. Any disparities were 
reconciled by discussion and a third reviewer included for unresolved discrepancies. The following characteristics were extracted: author, year and publication type; study name and design; country and region; sample size; treatment, dose schedule and treatment duration; baseline characteristics; median length of follow-up; efficacy measures (as summarized in Table 1) and health-related quality of life (HRQoL) as available.

\section{Critical appraisal \& bias}

Randomized controlled trials (RCTs) were assessed for quality and risk of bias using the National Institute for Health and Care Excellence (NICE) Single Technology Appraisal (STA) instrument [15]. Observational studies were assessed using the Newcastle-Ottawa Scale (NOS) [16]; however, quality and risk of bias were not assessed for abstracts from conference proceedings.

\section{Statistical analysis}

Results from RCTs and non-RCTs (nRCTs) were summarized using descriptive statistics, and median values were reported for continuous variables, where applicable. All descriptive analyses were conducted in Microsoft ${ }^{\circledR}$ Excel 2016. Median measures of efficacy were calculated as the mean of the two middlemost values after individual efficacy outcome measures were sorted into ascending order. Results were reported by risk categories according to MSKCC and IMDC prognostic scales. This was an exploratory analysis to provide an understanding of the relationship between prognostic risk categories and survival outcomes, hence inferential statistics were not calculated. Qualitative and narrative assessment were also performed to compare the differences in survival outcomes by treatment and prognostic risk categories.

\section{Results}

\section{Study selection \& characteristics}

A total of 1256 articles were identified by database searches and an additional 13 identified by hand screening. Duplicate studies $(n=370)$ were excluded and the titles and abstracts of 899 articles screened. 654 articles did not meet eligibility criteria and the whole text of 245 articles underwent screening. Of these, 47 articles were included for evidence synthesis. The article selection process is summarized in the PRISMA flow diagram (Figure 1).

Included studies and their characteristics are summarized in Table 2. Overall, 40 full-length articles and seven abstracts published in conference proceedings were included (clinical trials $=23$, observational studies $=24)$. The majority of publications were multinational $(\mathrm{n}=19)$, from Europe $(\mathrm{n}=15)$ or from North America $(\mathrm{n}=7)$ (Table 2). Other studies were based on populations in Japan, Brazil, China and India. One article did not report the country [17].

Of the single-agent treatments, sunitinib was the most frequently studied $(n=29)$, followed by IFN- $\alpha ; n=8$ and sorafenib $(n=6)$ (Supplementary Figure 2). Combination treatments were evaluated in 12 studies, of which bevacizumab plus IFN- $\alpha$ was the most common $(\mathrm{n}=4)$ (Supplementary Figure 2). Overall survival (OS), PFS and ORR were reported in 35,33 and 15 articles, respectively.

Overall, 19 studies stratified patients by IMDC alone and 21 studies by MSKCC alone. One study stratified patients by the Japanese Metastatic Renal Cancer (JMRC) and MSKCC [18] and a separate study reported outcomes stratified by the University of California Los Angeles-Survival After Nephrectomy Immunotherapy (UCLA-SANI) and MSKCC [19]. Five articles reported outcomes according to both MSKCC and IMDC [4,20-23].

\section{Efficacy by risk group}

Reported OS, PFS and ORR were greatest in patients with favorable risk, followed by intermediate and poor risk patients according to either MSKCC and IMDC (Figures 2-4).

\section{Overall survival}

Among RCTs and nRCTs $(n=6)$, the longest median OS was reported in patients with MSKCC favorable risk treated with sunitinib (not reached) or IFN- $\alpha$ (not reached). The longest reported median OS value was in patients with MSKCC favorable risk treated with IL-2/IFN- $\alpha$ (64.6 months; $95 \%$ confidence interval [CI] not reported). In patients with MSKCC intermediate risk, the longest median OS was reported for bevacizumab plus IL-2/IFN- $\alpha$ (27.4 months; 95\% CI: not reported). Sunitinib was associated with the longest median OS in patients with MSKCC poor risk (13.3 months; without prior nephrectomy; Figure 2A). 
Table 2. Characteristics of included articles.

\begin{tabular}{|c|c|c|c|c|c|c|}
\hline Study (year) & Country & Study design & Treatment groups $(n)$ & Prognostic model & Prior nephrectomy & Ref \\
\hline $\begin{array}{l}\text { Beuselinck (2018) } \\
\text { (Checkmate 214) }\end{array}$ & Multinational & RCT & Sunitinib (162) & IMDC & No & {$[55$} \\
\hline $\begin{array}{l}\text { Cella (2019) } \\
\text { (CheckMate 214) }\end{array}$ & Multinational & $\mathrm{RCT}$ & $\begin{array}{l}\text { Nivolumab plus ipilimumab (425) } \\
\text { Sunitinib (422) }\end{array}$ & IMDC & Yes & {$[56$} \\
\hline $\begin{array}{l}\text { Choueiri (2018) } \\
\text { (CABOSUN) }\end{array}$ & USA & $\mathrm{RCT}$ & $\begin{array}{l}\text { Cabozantinib (79) } \\
\text { Sunitinib (78) }\end{array}$ & IMDC & Yes & {$[30$} \\
\hline $\begin{array}{l}\text { Choueiri (2019) } \\
\text { (JAVELIN Renal 101) }^{\dagger}\end{array}$ & Multinational & $\mathrm{RCT}$ & $\begin{array}{l}\text { Avelumab plus axitinib (442) } \\
\text { Sunitinib (444) }\end{array}$ & MSKCC/IMDC & No & {$[20$} \\
\hline $\begin{array}{l}\text { Donskov (2018) } \\
\text { (DaRenCa) }\end{array}$ & Denmark & $\mathrm{RCT}$ & $\begin{array}{l}\text { IL-2/IFN- } \alpha / \text { Bevacizumab (59) } \\
\text { II-2/IFN- } \alpha(59)\end{array}$ & MSKCC & Yes & {$[57$} \\
\hline $\begin{array}{l}\text { Eichelberg (2015) } \\
\text { (SWITCH) }\end{array}$ & Europe & RCT & $\begin{array}{l}\text { Sorafenib (182) } \\
\text { Sunitinib (183) }\end{array}$ & MSKCC & Yes & {$[58$} \\
\hline $\begin{array}{l}\text { Escudier (2007) } \\
\text { (AVOREN) }\end{array}$ & Multinational & $\mathrm{RCT}$ & $\begin{array}{l}\text { Bevacizumab plus IFN- } \alpha 2 a(327) \\
\text { IFN- } \alpha 2 a(322)\end{array}$ & MSKCC & No & {$[59$} \\
\hline $\begin{array}{l}\text { Escudier (2010) } \\
\text { (AVOREN) }\end{array}$ & Multinational & RCT & $\begin{array}{l}\text { Bevacizumab plus IFN- } \alpha 2 a \text { (327) } \\
\text { IFN- } \alpha 2 a(322)\end{array}$ & MSKCC & Yes & {$[60$} \\
\hline Hudes (2007) & Multinational & RCT & $\begin{array}{l}\text { Temsirolimus (209) } \\
\text { IFN- } \alpha \text { (207) } \\
\text { IFN- } \alpha \text { plus Temsirolimus (210) }\end{array}$ & MSKCC & Yes & {$[61$} \\
\hline $\begin{array}{l}\text { Hutson (2013) } \\
\text { (AGILE) }\end{array}$ & Multinational & RCT & $\begin{array}{l}\text { Axitinib (192) } \\
\text { Sorafenib (96) }\end{array}$ & MSKCC & Yes & {$[62$} \\
\hline $\begin{array}{l}\text { Méjean (2018) } \\
\text { (CARMENA) }\end{array}$ & Europe & $\mathrm{RCT}$ & Sunitinib (224) & MSKCC & Yes & {$[63$} \\
\hline Motzer (2007) & Multinational & $\mathrm{RCT}$ & Sunitinib (375) & MSKCC & Yes & {$[3$} \\
\hline Motzer (2009) & Multinational & RCT & $\begin{array}{l}\text { IFN- } \alpha \text { (375) } \\
\text { Sunitinib (375) }\end{array}$ & MSKCC & Yes & {$[64$} \\
\hline Motzer (2013) & Multinational & RCT & $\begin{array}{l}\text { Tivozanib (260) } \\
\text { Sorafenib (257) }\end{array}$ & MSKCC & No & {$[65$} \\
\hline $\begin{array}{l}\text { Motzer (2018) } \\
\text { (CheckMate 214) }\end{array}$ & Multinational & RCT & $\begin{array}{l}\text { Nivolumab plus ipilimumab (425) } \\
\text { Sunitinib (422) }\end{array}$ & IMDC & Yes & {$[5$} \\
\hline $\begin{array}{l}\text { Motzer (2019) } \\
\text { (JAVELIN Renal 101) }\end{array}$ & Multinational & RCT & $\begin{array}{l}\text { Avelumab plus axitinib (442) } \\
\text { Sunitinib (444) }\end{array}$ & MSKCC/IMDC & Yes & {$[4$} \\
\hline $\begin{array}{l}\text { Rini (2008) } \\
\text { (CALGB 90206) }\end{array}$ & Canada and USA & RCT & $\begin{array}{l}\text { Bevacizumab + IFN- } \alpha(369) \\
\text { IFN- } \alpha(363)\end{array}$ & MSKCC & Yes & {$[66$} \\
\hline $\begin{array}{l}\text { Rini (2019) } \\
\text { (KEYNOTE-426) }\end{array}$ & Multinational & RCT & $\begin{array}{l}\text { Pembrolizumab plus axitinib (432) } \\
\text { Sunitinib (429) }\end{array}$ & IMDC & Yes & {$[6$} \\
\hline $\begin{array}{l}\text { Tannir }(2019)^{\dagger} \\
\text { (Checkmate 214) }\end{array}$ & Multinational & $\mathrm{RCT}$ & $\begin{array}{l}\text { Nivolumab plus ipilimumab (550) } \\
\text { Sunitinib (546) }\end{array}$ & IMDC & No & {$[67$} \\
\hline Boegemann (2018) & Germany & Observational & Sunitinib (SS [199] and SM [98]) & IMDC & Yes & {$[68$} \\
\hline Bozkurt (2015) & Turkey & Observational & Sunitinib (86) & MSKCC & Yes & {$[69$} \\
\hline Coelho (2016) & Brazil & Observational & Sunitinib (58) & MSKCC & Yes & {$[70$} \\
\hline De Giorgi (2014) & Turkey & Observational & Sunitinib (181) & IMDC & Yes & {$[25$} \\
\hline De Giorgi (2014) & Turkey & Observational & Sunitinib (SR [123] and AR [62]) & IMDC & Yes & {$[71$} \\
\hline Harshman (2014) & Multinational & Observational & $\begin{array}{l}\text { Everolimus (93) } \\
\text { Temsirolimus (34) }\end{array}$ & IMDC & Yes & {$[72$} \\
\hline Heng (2009) & Canada & Observational & $\begin{array}{l}\text { IFN- } \alpha(131) \\
\text { Sunitinib (69) }\end{array}$ & MSKCC & Yes & {$[43$} \\
\hline lacovelli (2018) & Italy & Observational & Sunitinib (457) & IMDC & Yes & {$[38$} \\
\hline $\begin{array}{l}\text { Joshi (2016) } \\
\text { (CTRI) }\end{array}$ & India & Observational & Sorafenib (82) & IMDC & Yes & {$[73$} \\
\hline Kubackova (2015) & Czech Republic & Observational & Sunitinib (495) & MSKCC/IMDC & Yes & {$[21$} \\
\hline Lalani (2017) & Canada & Observational & $\begin{array}{l}\text { Pazopanib (93) } \\
\text { Sunitinib (577) }\end{array}$ & IMDC & Yes & {$[74$} \\
\hline Lolli (2016) & Italy & Observational & Sunitinib (335) & MSKCC/IMDC & No & {$[22$} \\
\hline Omae (2016) & Japan & Observational & Sorafenib (20) & MSKCC & Yes & {$[75$} \\
\hline
\end{tabular}


Table 2. Characteristics of included articles (cont.).

\begin{tabular}{|c|c|c|c|c|c|c|}
\hline Study (year) & Country & Study design & Treatment groups (n) & Prognostic model & Prior nephrectomy & Ref. \\
\hline $\begin{array}{l}\text { Perez-Valderrama (2016) } \\
\text { (SPAZO) }\end{array}$ & Spain & Observational & Pazopanib (278) & IMDC & Yes & [76] \\
\hline Rini (2018) & Multinational & Observational & Sunitinib (375) & MSKCC/IMDC & Yes & [23] \\
\hline Santoni (2015) & Italy & Observational & $\begin{array}{l}\text { Sunitinib (190) } \\
\text { Sorafenib (58) }\end{array}$ & MSKCC & No & [77] \\
\hline Sastre-Heres (2014) & Spain & Observational & $\begin{array}{l}\text { Sunitinib (51) } \\
\text { Temsirolimus (14) }\end{array}$ & MSKCC & No & [78] \\
\hline Savard $(2019)^{\dagger}$ & & Observational & Sunitinib (1769) & IMDC & Yes & [17] \\
\hline $\begin{array}{l}\text { Schmidinger }(2019)^{\dagger} \\
\text { (ADONIS) }\end{array}$ & Europe & Observational & Sunitinib (467) & IMDC & No & [79] \\
\hline Shinohara (2012) & Japan & Observational & IFN- $\alpha(361)$ & MSKCC/JMRC & Yes & [18] \\
\hline Stenehjem (2016) & USA & Observational & HD IL-2 (391) & IMDC & Yes & [80] \\
\hline Warren (2009) & Canada & Observational & IFN- $\alpha(141)$ & MSKCC & Yes & [81] \\
\hline Yildiz (2013) & Turkey & Observational & Sunitinib (77) & MSKCC & Yes & [82] \\
\hline Zhang (2018) & China & Observational & Sunitinib (30) & IMDC & Yes & [83] \\
\hline $\begin{array}{l}\text { McDermott (2015) } \\
\text { (SELECT) }\end{array}$ & USA & $\mathrm{nRCT}$ & IL-2 (120) & MSKCC/UCLA-SANI & No & [19] \\
\hline $\begin{array}{l}\text { McDermott }(2018)^{\dagger} \\
(\text { KEYNOTE-427) }\end{array}$ & Multinational & $\mathrm{nRCT}$ & Pembrolizumab (107) & IMDC & No & [84] \\
\hline Melichar (2013) (BEVLiN) & Multinational & $\mathrm{nRCT}$ & Bevacizumab plus IFN- $\alpha$ (146) & MSKCC & Yes & [85] \\
\hline $\begin{array}{l}\text { Zurita }(2018)^{\dagger} \\
(T e m P a)\end{array}$ & Multinational & $\mathrm{nRCT}$ & $\begin{array}{l}\text { Pazopanib (35) } \\
\text { Temsirolimus (34) }\end{array}$ & IMDC & No & [86] \\
\hline
\end{tabular}

${ }^{\dagger}$ Articles identified from conference proceedings.

AR: Alternative/adapted regimen; HD: High dose; IMDC: International Metastatic RCC Database Consortium; JMRC: Japanese Metastatic Renal Cancer; MSKCC: Memorial Sloan Kettering Cancer Center; nRCT: Nonrandomized controlled trial; RCT: Randomized controlled trial; SM: Subsequent treatment modification; SR: Standard regimen; SS: Standard dose/schedule; UCLA-SANI: University of California Los Angeles-Survival After Nephrectomy Immunotherapy.
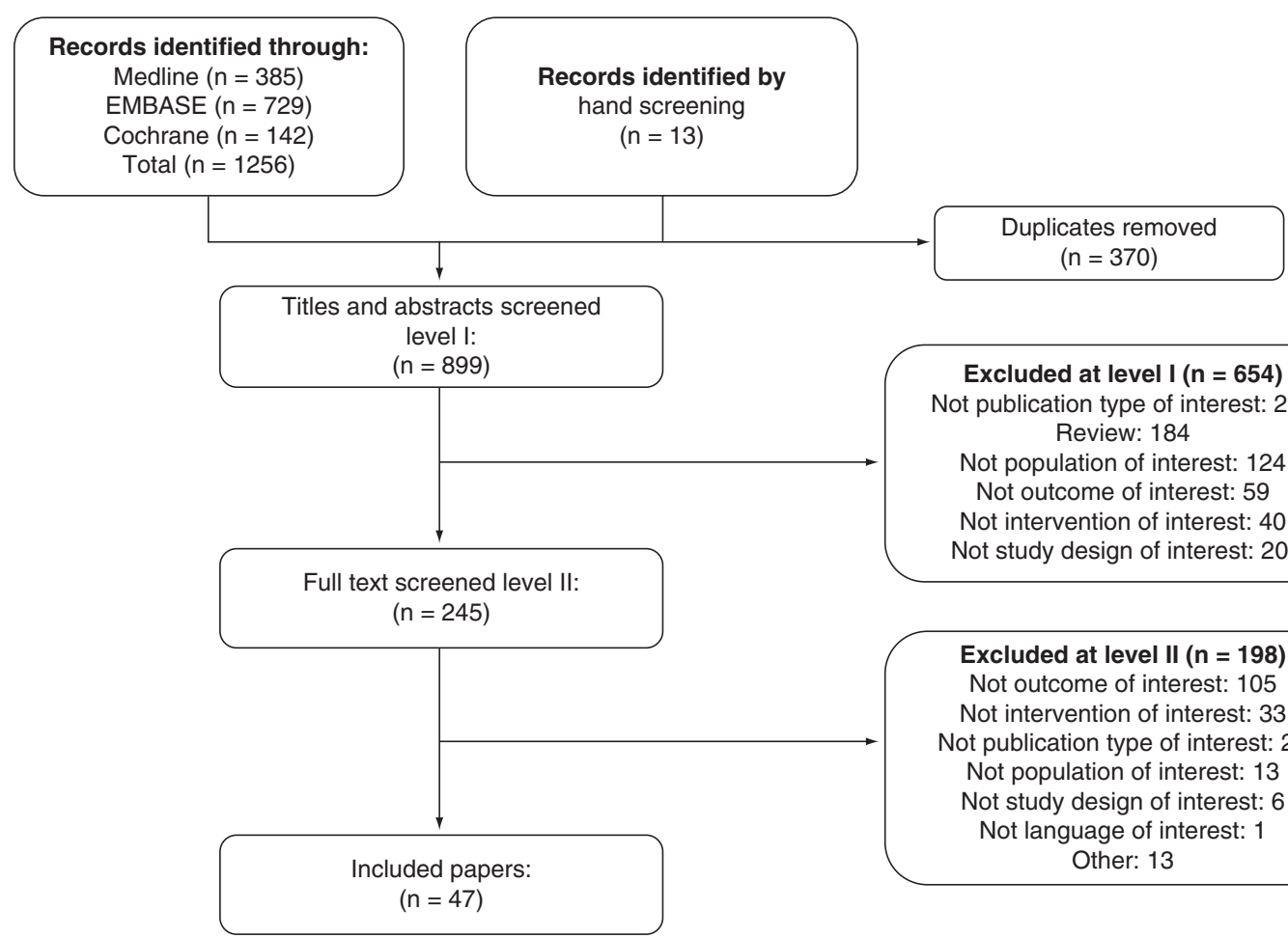

Excluded at level I $(n=654)$ Not publication type of interest: 227 Review: 184

Not population of interest: 124

Not outcome of interest: 59

Not intervention of interest: 40

Not study design of interest: 20

Figure 1. PRISMA flow diagram of the systematic literature review process. 
(A)

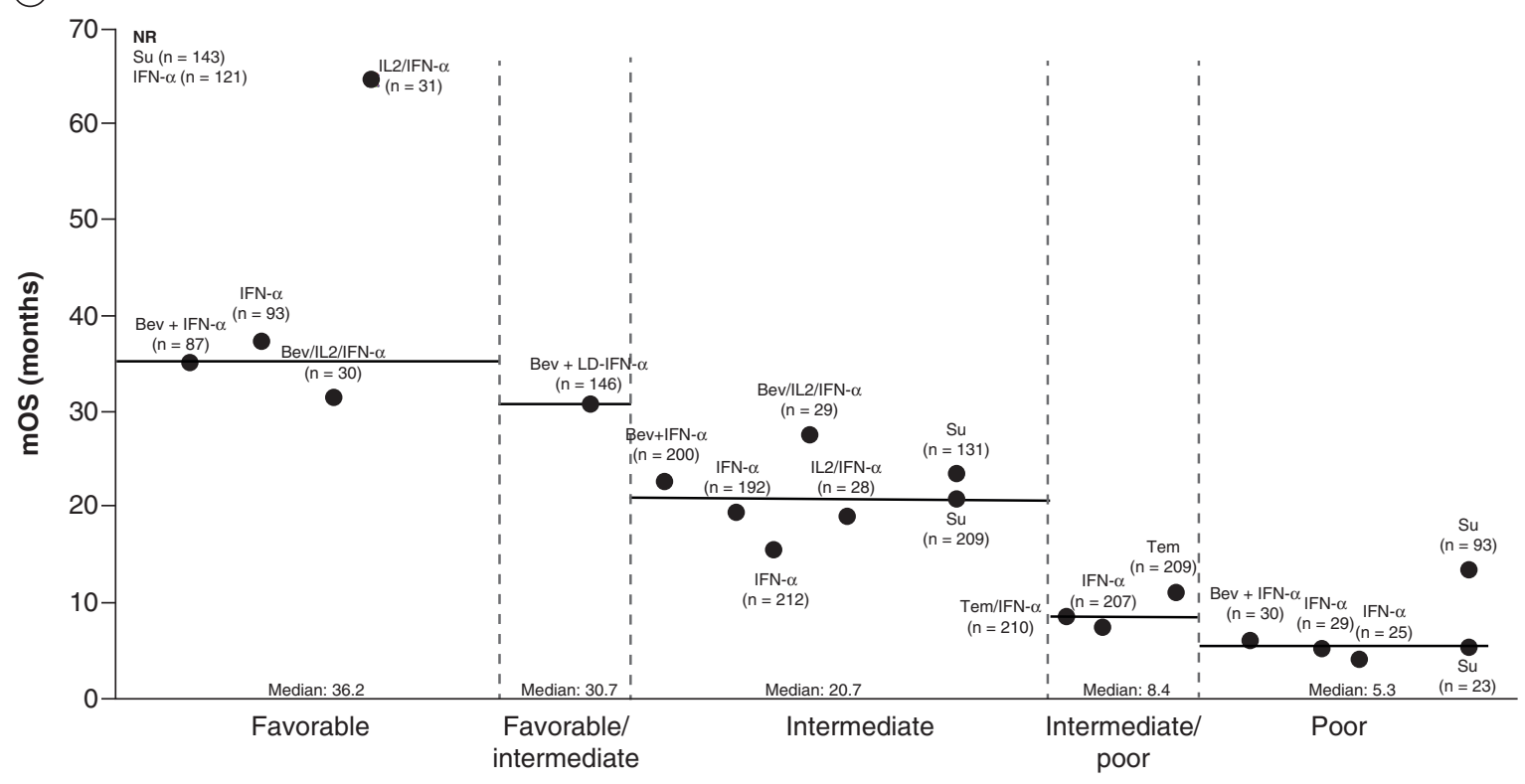

(B)

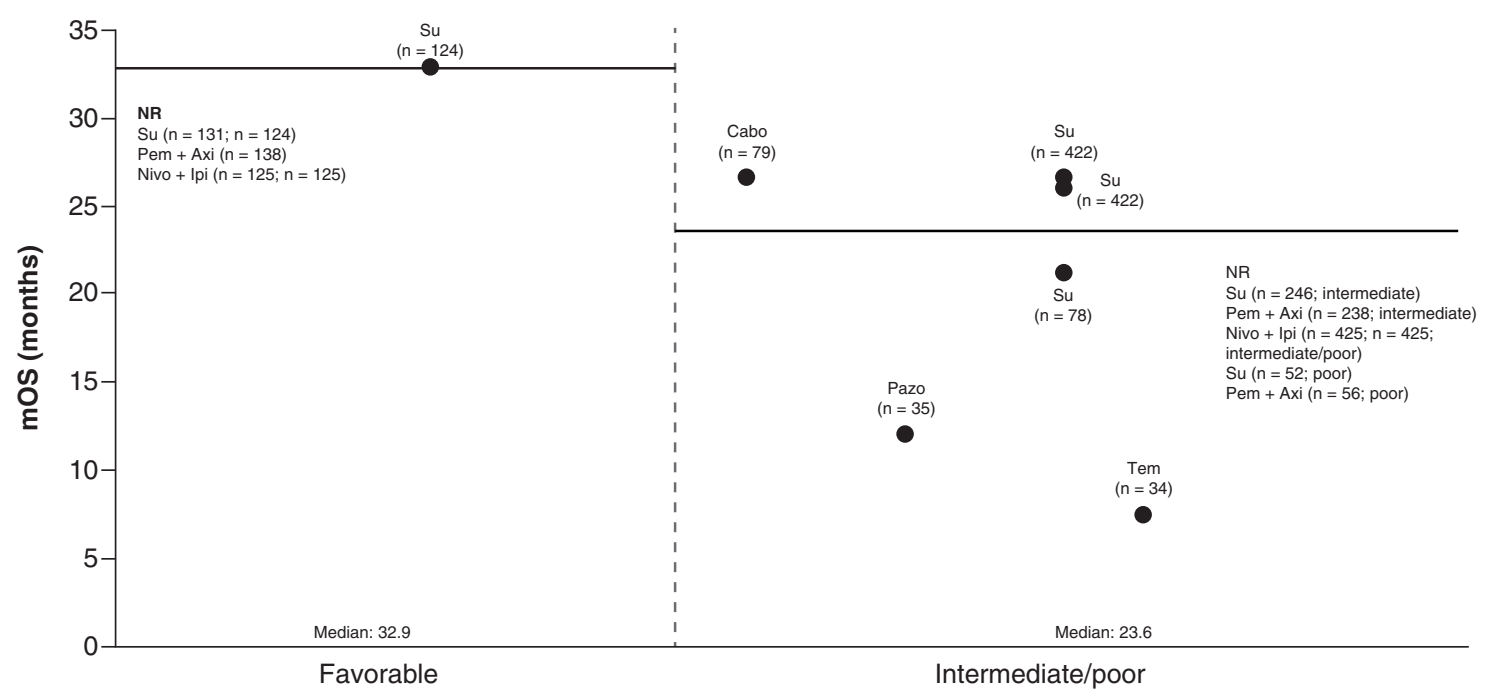

Figure 2. Median verall survival in patients with metastatic renal cell carcinoma by treatment and according to (A) Memorial Sloan Kettering Cancer Center and (B) International Metastatic RCC Database Consortium risk groups as reported in randomized controlled trials and randomized controlled trials.

Bev+IFN-2 $\alpha$ : Bevacizumab plus interferon 2-alpha; IMDC: International Metastatic Renal Cell Carcinoma Database Consortium; LD-IFN: Low-dose interferon; mRCC: Metastatic renal cell carcinoma; MSKCC: Memorial Sloan-Kettering Cancer Center; Nivo+Ipi: Nivolumab plus ipilimumab; OS: Overall survival; Pazo: Pazopanib; Pem+Axi:

Pembrolizumab plus axitinib; NR: Not reached; nRCT: Non-randomized controlled trial; RCT: Randomized controlled trial; Su: Sunitinib; Tem: Temsirolimus.

Among observational studies $(\mathrm{n}=11)$, the longest median OS was reported in patients with MSKCC favorable risk treated with sorafenib at 77.7 months (95\% CI: 47.7-not reached). In MSKCC intermediate risk patients, sunitinib was reported to have the longest median OS at 40.2 months (95\% CI: 25.5-not reached). In MSKCC poor risk patients, sunitinib was associated with the longest median OS at 16.9 months (95\% CI: 6.1-not reached).

Five RCTs or nRCTs, and eight observational studies, reported OS according to IMDC risk groups. In RCTs and nRCTs, OS was not reached in studies evaluating sunitinib, pembrolizumab plus axitinib, and nivolumab plus ipilimumab across all risk groups (Figure 2B). Among observational studies, median OS for favorable risk 
(A)

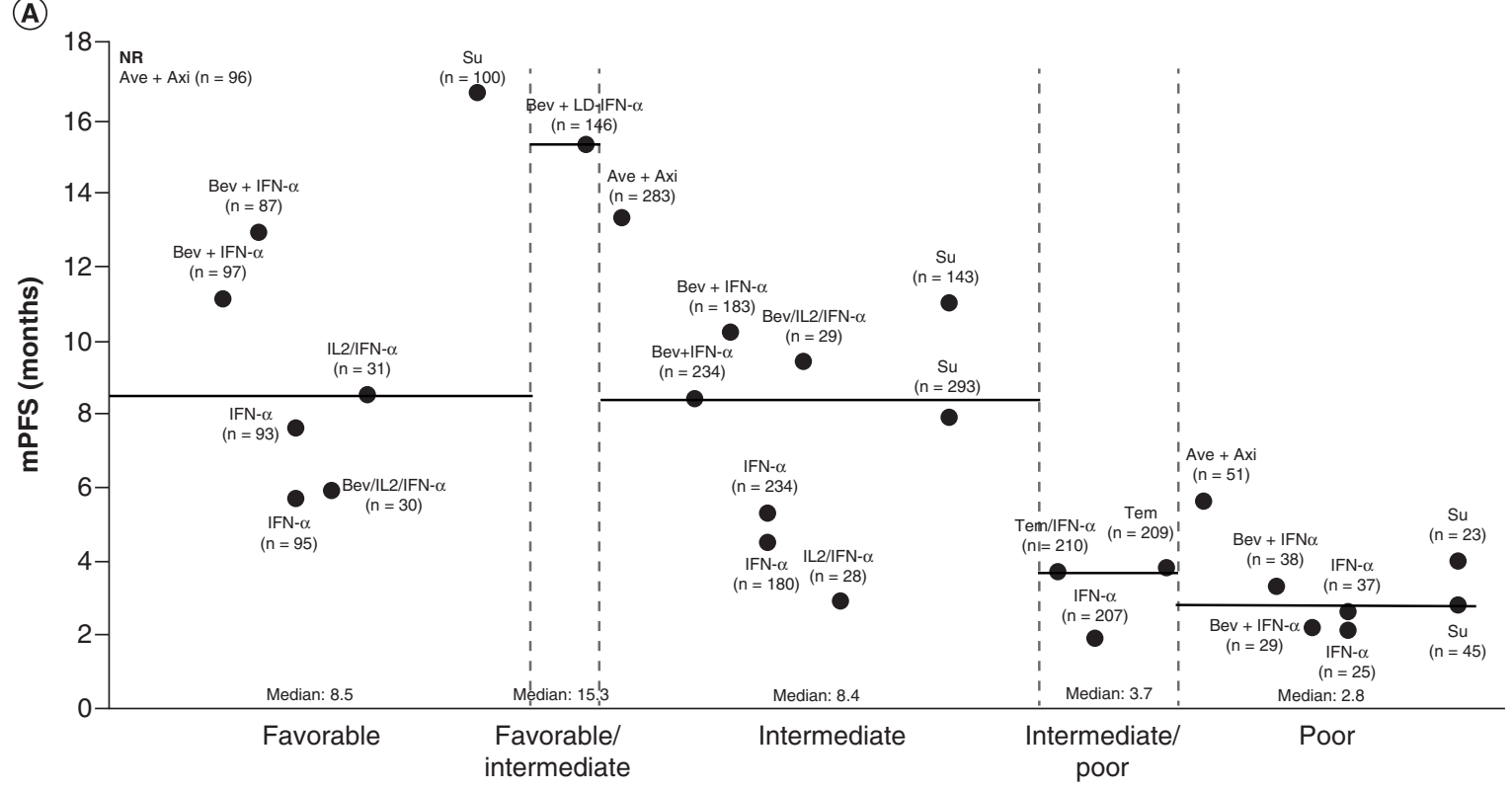

(B)

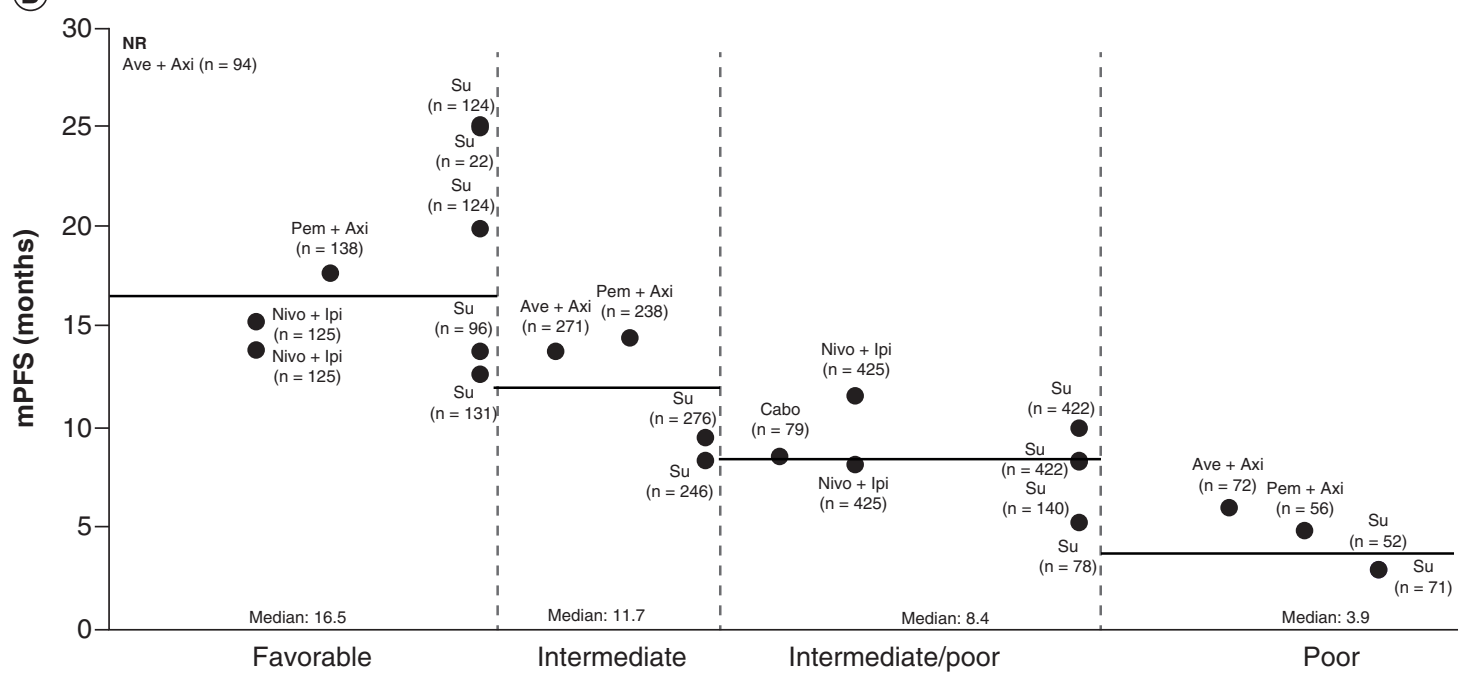

Figure 3. Median progression-free survival in patients with metastatic renal cell carcinoma by treatment and according to (A) Memorial Sloan Kettering Cancer Center and (B) International Metastatic RCC Database Consortium risk group as reported in randomized controlled trials and nonrandomized controlled trials.

Ave+Axi: Avelumab plus axitinib; Bev+IFN: Bevacizumab plus interferon-alpha; IMDC: International Metastatic Renal Cell Carcinoma Database Consortium; LDIFN: Low-dose interferon; mRCC: Metastatic renal cell carcinoma; MSKCC: Memorial Sloan-Kettering Cancer Center; Nivo+ipi: Nivolumab plus ipilimumab; Pazo: Pazopanib; Pem+Axi: Pembrolizumab plus axitinib; PFS: Progression-free survival; NR: not reached; nRCT: Non-randomized controlled trial; RCT: Randomized controlled trial; Su: Sunitinib; Tem: Temsirolimus.

patients treated with sunitinib was 97.1 months (95\% CI: 46.3-not reached). In the poor risk group, median OS for patients treated with sunitinib was 37.0 months (95\% CI: 4.0-69.0).

\section{Progression-free survival}

Seven RCTs or nRCTs and eight observational studies stratified patients according to MSKCC. Among RCTs and nRCTs, PFS was longest for avelumab plus axitinib (not reached). The longest reported PFS value was from the same study with sunitinib treatment in the favorable risk group (16.7 months; 95\% CI: 11.1-18.6). In the intermediate and poor risk groups, PFS was longest for avelumab plus axitinib at 13.3 (95\% CI: 8.5-not reached) 
(A)

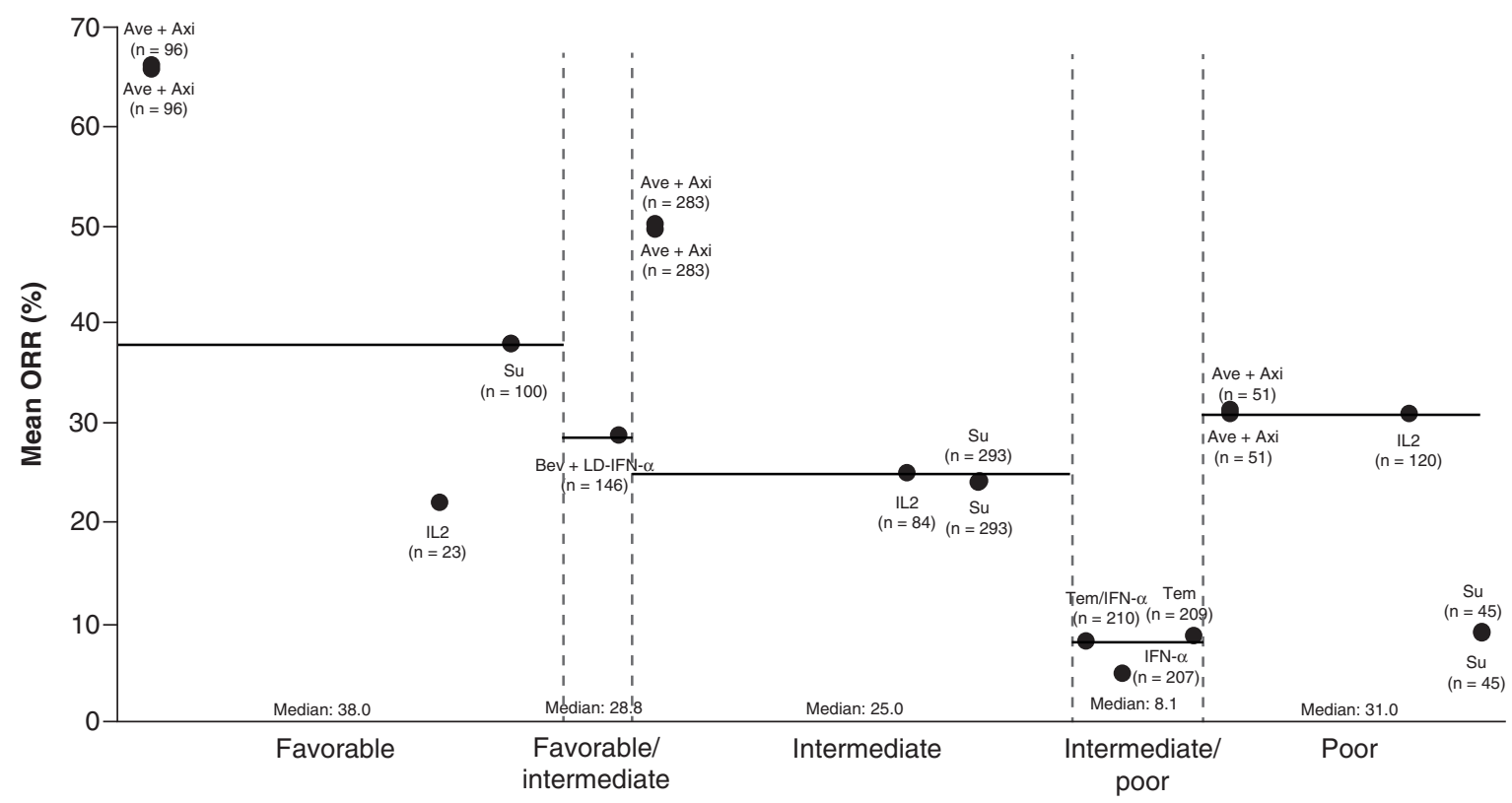

(B)

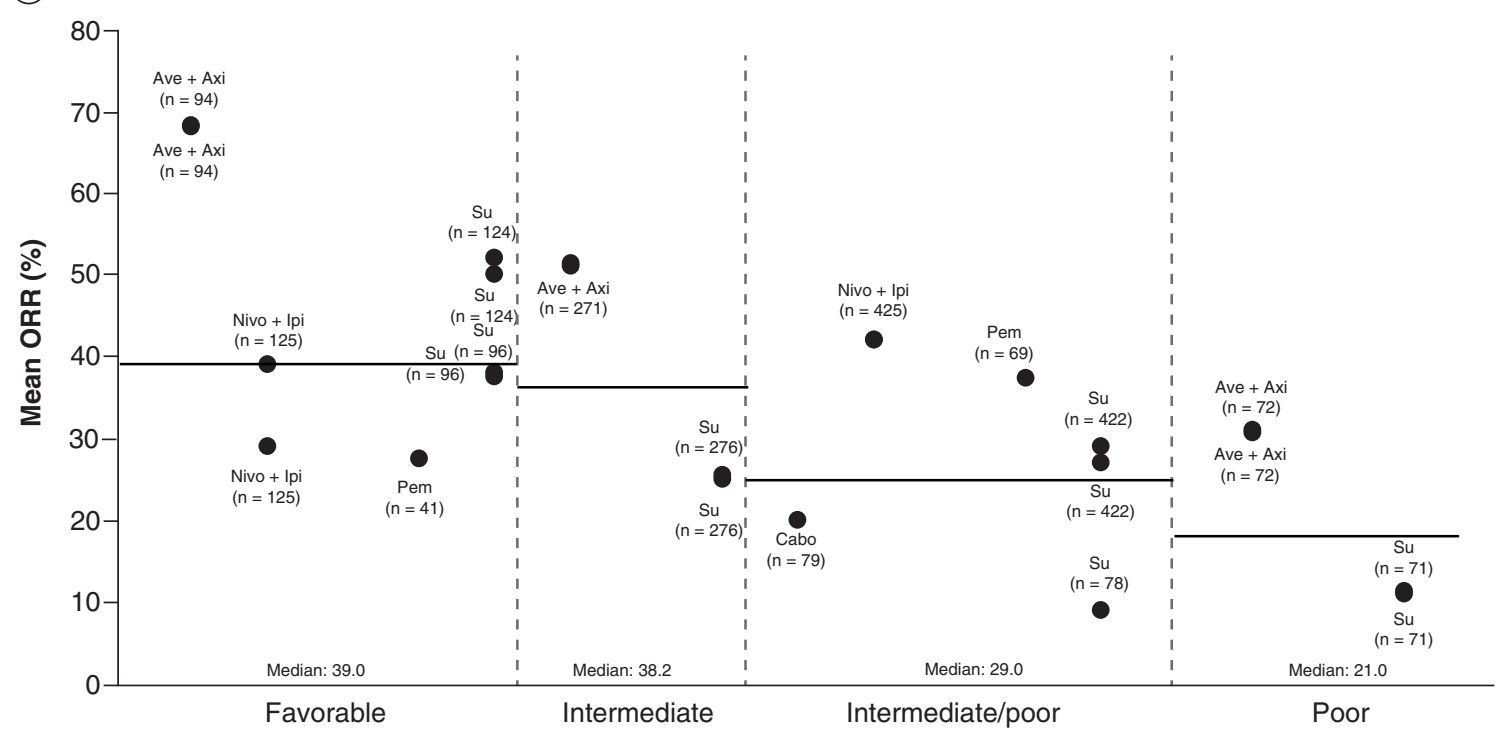

Figure 4. Median objective response rate in patients with metastatic renal cell carcinoma by treatment and according to (A) Memorial Sloan Kettering Cancer Center and (B) International Metastatic RCC Database Consortium risk group as reported in randomized controlled trials and nonrandomized controlled trials.

Ave+Axi: Avelumab plus axitinib; Bev+LD-IFN: Bevacizumab plus low-dose interferon; IMDC: International Metastatic Renal Cell Carcinoma Database Consortium; mRCC: Metastatic renal cell carcinoma; MSKCC: Memorial Sloan-Kettering Cancer Center; Nivo+ipi: Nivolumab plus ipilimumab; ORR: Objective response rate; Pem: Pembrolizumab; Pem+Axi: Pembrolizumab plus axitinib; nRCT: Non-randomized controlled trial; RCT: Randomized controlled trial; Su: Sunitinib; Tem: Temsirolimus.

and 5.6 (95\% CI: 2.6-11.2) months, respectively (Figure 3A). Of observational studies, the longest PFS was reported for sunitinib at 36.4 months (95\% CI: 21.1-44.7), 21 months (95\% CI: 12.1-29.9) and 6.0 months (95\% CI: 4.1-7.8) for patients with favorable, intermediate and poor risk, respectively.

Of studies that stratified patients according to IMDC, PFS according to risk group was reported in six RCTs or nRCTs, and 12 observational studies. As reported in RCTs and nRCTs, PFS was longest for avelumab plus axitinib (not reached) in the favorable risk group. In the IMDC intermediate group, PFS was longest for pembrolizumab 


\begin{tabular}{|c|c|c|c|c|c|}
\hline Study (year) (risk model) ${ }^{\dagger}$ & Treatment (n) & PD-L1 positive, $\mathrm{n}(\%)$ & mPFS (months) & ORR (\%) & Ref. \\
\hline \multirow[t]{2}{*}{$\begin{array}{l}\text { Choueiri et al. (2019) } \\
\text { (MSKCC) }\end{array}$} & Avelumab plus axitinib, 442 & $270(61)$ & $\begin{array}{l}\text { Favorable: NR } \\
\text { Intermediate: } 13.3 \\
\text { Poor: } 5.6\end{array}$ & $\begin{array}{l}\text { Favorable: } 66 \\
\text { Intermediate: } 50 \\
\text { Poor: } 31\end{array}$ & {$[20]$} \\
\hline & Sunitinib, 444 & $290(65)$ & $\begin{array}{l}\text { Favorable: } 16.7 \\
\text { Intermediate: } 7.9 \\
\text { Poor: } 2.8\end{array}$ & $\begin{array}{l}\text { Favorable: } 38 \\
\text { Intermediate: } 24 \\
\text { Poor: } 9\end{array}$ & \\
\hline \multirow[t]{2}{*}{$\begin{array}{l}\text { Choueiri et al. (2019) } \\
\text { (IMDC) }\end{array}$} & Avelumab plus axitinib, 442 & $270(61)$ & $\begin{array}{l}\text { Favorable: NR } \\
\text { Intermediate: } 13.8 \\
\text { Poor: } 6\end{array}$ & $\begin{array}{l}\text { Favorable: } 68 \\
\text { Intermediate: } 51 \\
\text { Poor: } 31\end{array}$ & [20] \\
\hline & Sunitinib, 444 & $290(65)$ & $\begin{array}{l}\text { Favorable: } 13.8 \\
\text { Intermediate: } 8.4 \\
\text { Poor: } 2.9\end{array}$ & $\begin{array}{l}\text { Favorable: } 38 \\
\text { Intermediate: } 25 \\
\text { Poor: } 11\end{array}$ & \\
\hline \multirow[t]{2}{*}{$\begin{array}{l}\text { Motzer et al. (2019) } \\
\text { (MSKCC) }\end{array}$} & Avelumab plus axitinib, 442 & $270(61)$ & All risk groups: 13.8 & $\begin{array}{l}\text { Favorable: } 75 \\
\text { Intermediate: } 52.2 \\
\text { Poor: } 36.4\end{array}$ & [4] \\
\hline & Sunitinib, 444 & $290(65)$ & All risk groups: 7.2 & $\begin{array}{l}\text { Favorable: } 33.3 \\
\text { Intermediate: } 25.4 \\
\text { Poor: } 12.5\end{array}$ & \\
\hline \multirow[t]{2}{*}{$\begin{array}{l}\text { Motzer et al. (2019) } \\
\text { (IMDC) }\end{array}$} & Avelumab plus axitinib, 442 & $270(61)$ & All risk groups: 13.8 & $\begin{array}{l}\text { Favorable: } 76.9 \\
\text { Intermediate: } 52.6 \\
\text { Poor: } 38.6\end{array}$ & [4] \\
\hline & Sunitinib, 444 & $290(65)$ & All risk groups: 7.2 & $\begin{array}{l}\text { Favorable: } 33.9 \\
\text { Intermediate: } 25.1 \\
\text { Poor: } 15.4\end{array}$ & \\
\hline \multirow[t]{2}{*}{$\begin{array}{l}\text { Rini et al. (2019) } \\
\text { (IMDC) }\end{array}$} & $\begin{array}{l}\text { Pembrolizumab plus axitinib, } \\
432\end{array}$ & $243(59)$ & $\begin{array}{l}\text { Favorable: } 17.7 \\
\text { Intermediate: } 14.5 \\
\text { Poor: } 4.9\end{array}$ & All risk groups: 59.3 & [6] \\
\hline & Sunitinib, 429 & $254(62)$ & $\begin{array}{l}\text { Favorable: } 12.7 \\
\text { Intermediate: } 9.5 \\
\text { Poor: } 2.9\end{array}$ & All risk groups: 35.7 & \\
\hline
\end{tabular}

plus axitinib at 14.5 months (95\% CI: 12.4-18.0). In the IMDC poor risk group, the longest PFS was 6.0 months (95\% CI: 3.6-8.7) reported for patients who received avelumab plus axitinib (Figure 3B). Among observational studies, the longest PFS was 32.4 months (95\% CI: 14.0-50.0) for pazopanib. Sunitinib treatment was reported to have the longest PFS in the IMDC intermediate risk group (30.0 months; $95 \% \mathrm{CI}: 5.0-78.0)$ and the IMDC poor risk group (14.0 months; 95\% CI: 4.0-63.0).

\section{Objective response rate}

Eight articles (five RCTS or nRCTS; three observational studies) reported ORR according to MSKCC risk group. Of RCTs and nRCTs, ORR was highest in patients treated with avelumab plus axitinib in the favorable $(65.6 \%)$, intermediate (49.5\%) and poor (31.4\%) risk groups (Figure 4A). An ORR of 31\% was also reported for poor risk patients treated with IL-2. Of the included observational studies, patients treated with sunitinib had the highest ORR in the favorable $(50.7 \%)$, intermediate $(35.6 \%)$ and poor $(28.9 \%)$ risk groups.

Of studies that stratified by IMDC, six RCTs or nRCTs and three observational studies reported ORR according to risk group. Avelumab plus axitinib treatment was associated with the highest ORR among RCTs and nRCTs in the IMDC favorable risk group (68.1\%), intermediate risk group (51.3\%) and poor risk group (30.6\%) (Figure 4B). Among observational studies, sunitinib treatment was associated with the highest ORR in the IMDC favorable risk group (96.4\%), intermediate risk group (65.7\%) and poor risk group $(59.1 \%)$.

\section{PD-L1}

Of the included articles, four (all RCTs) reported outcomes according to PD-L1 status and risk group. PD-L1 positivity was defined as an evaluable PD-L1 expression $\geq 1 \%$. Available outcomes and PD-L1 status by treatment arm are summarized in Table 3. Overall, outcomes in patients with PD-L1 positive tumors were similar to those reported in the overall population. In the PD-L1-positive population, the combinations avelumab plus axitinib and pembrolizumab plus axitinib demonstrated superior PFS and ORR compared with sunitinib. 
Quality \& risk of bias

All RCTs had a low risk of bias for 'randomization,' 'similarity of groups at baseline' and 'more outcomes than reported'; however, there was a high risk of bias for the domains 'concealment of allocation' and 'blinded to allocation' in 12/16 and 13/16 articles, respectively. Risk of bias for 'intent-to-treat' and 'drop out imbalance' were generally, but not universally, low (Supplementary Figure 1).

The total NOS score for nRCTs ranged from 5-9, indicating that articles were of a moderate-to-high quality (Supplementary Figure 2). All nRCTs demonstrated that they were designed to be representative of the exposed cohort, outcomes were not present at the start of the study, reported all predefined outcomes, had sufficient followup for the outcomes and had an adequate patient follow-up. None of the articles reported selection criteria for the non-exposed cohort.

\section{Discussion}

The treatment of mRCC has recently undergone dramatic change and it is important to summarize and evaluate the available evidence to help facilitate effective treatment selection. Our analysis identified 47 articles that evaluated the efficacy and effectiveness of first-line mRCC treatments according to stratification by relevant prognostic models. The majority of these articles (45/47) included analysis of TKIs and/or anti-VEGF-targeted treatments, with sunitinib as the most commonly investigated treatment. Comparatively, 12 studies evaluated immuno-oncology treatments. Following approval of immune checkpoint and immune checkpoint/TKI combinations, treatment guidelines, including ESMO and NCCN, updated their recommendations, differentiating treatment according to risk group [7,8]. Standard of care, or preferred regimens, for patients with clear cell mRCC favorable risk include pembrolizumab plus axitinib, sunitinib, pazopanib, bevacizumab plus IFN- $\alpha$ and tivozanib $[7,8]$. For patients with intermediate/poor risk, preferred regimens are nivolumab plus ipilimumab, pembrolizumab plus axitinib and cabozantinib $[7,8]$. Other recommended regimens for favorable risk patients include ipilimumab plus nivolumab, cabozantinib, avelumab plus axitinib, high dose IL-2 and bevacizumab plus IFN. Other recommended regimens for patients with intermediate/poor risk are avelumab plus axitinib, sunitinib, pazopanib, cabozantinib, tivozanib, bevacizumab plus IFN and temsirolimus. To optimize treatment outcomes, it is vital that clinicians routinely evaluate patient risk according to established prognostic models. Overall, the efficacy and effectiveness as reported by the articles included in this analysis were consistent with the updated recommendations.

In RCTs and nRCTs, sunitinib and IFN- $\alpha$ were reported to have the longest median OS (not reached) for patients with favorable risk stratified by either IMDC or MSKCC. Pembrolizumab plus axitinib and nivolumab plus ipilimumab, also reported that OS was not reached in their Phase III trials according to IMDC risk groups [5,6]. This suggests sunitinib may still have a role in first-line treatment for patients with mRCC and favorable risk, or in patients unable to receive immuno-oncology therapies. This was evident in the Phase III Checkmate 214 RCT (ClinicalTrials.gov: NCT02231749), where sunitinib displayed a significantly higher ORR (52\% vs 29\%; p < 0.001) and longer median PFS (25.1 vs 15.3 months; $\mathrm{p}<0.001)$ compared with nivolumab plus ipilimumab in patients with favorable risk [5]. However, in the Phase III RCTs JAVELIN Renal 101 (NCT02684006) and KEYNOTE426 (NCT02853331), the combinations of avelumab plus axitinib and pembrolizumab plus axitinib, respectively, demonstrated improved efficacy outcomes compared with sunitinib across all risk groups [4,6]. Similarly, in patients with favorable risk the longest PFS in RCTs and nRCTs was with avelumab plus axitinib (not reached), followed by sunitinib (IMDC, 25.1 months; MSKCC, 16.7 months). For intermediate and poor risk groups, TKI/immuno-oncology combinations provided the greatest PFS benefit. Avelumab plus axitinib reported the longest PFS according to MSKCC at 13.3 months in intermediate patients and 5.6 months in poor risk patients. According to IMDC, pembrolizumab plus axitinib reported the longest PFS for intermediate patients of 14.5 months. For patients with IMDC poor risk, avelumab plus axitinib reported the longest PFS of 6.0 months. According to MSKCC or IMDC, avelumab plus axitinib reported the highest ORR for each individual risk group; however, ORR by individual risk group was not reported for pembrolizumab plus axitinib in the KEYNOTE-426 trial (NCT02853331). Overall ORR was highest with pembrolizumab plus axitinib compared with avelumab plus axitinib or nivolumab plus ipilimumab; however, a greater proportion of these patients were of favorable risk (31\%) compared with the other two combinations (21 and 23\%, respectively), which may partly account for these differences [4-6]. Although direct comparisons of these three combinations are not available, it is notable that with the combination nivolumab plus ipilimumab the proportion of patients achieving a complete response is higher $(10 \%)$ than in patients treated with avelumab plus axitinib (3\%) or pembrolizumab plus axitinib (5.8\%) [4-6]. 
Without further exploration, it is likely that other combinations remain the preferred regimen in favorable risk patients.

The efficacy of the mRCC treatments in clinical trials appeared to be similar to the reported effectiveness in observational studies. This is consistent with other analyses, which suggest a role for real-world data as a complementary source of evidence to RCTs to aid clinical decision-making [24]. The exception may be the ORR for sunitinib reported by Di Giorgi et al. [25], which appeared to be substantially higher than that reported in clinical trials. This may be related to other prognostic factors than those included in IMDC or MSKCC models; $16 \%$ of patients in this study had lymphopenia, which was associated with increased OS [25]. In general, patients with mRCC treated in real-world practice are more likely to be poor risk by MSKCC and have lower Eastern Cooperative Oncology Group Performance Score (ECOG PS) compared with patients enrolled in Phase III studies [26]. Trialineligible patients may also have substantial comorbidities such as brain metastases or other concurrent malignancies, which has been reported to result in inferior PFS and OS compared with trial-eligible patients [27-29]. It is therefore reassuring that real-world outcomes were comparable with those of RCTs, as there is often limited evidence for certain patient populations to help inform treatment choice.

As expected, outcomes varied according to risk group. As previously noted, the higher proportion of favorable risk patients in KEYNOTE-426 (NCT02853331) compared with JAVELIN Renal 101 (NCT02684006) may account for the slightly higher PFS and ORR outcomes reported for pembrolizumab plus axitinib [4,6]. In contrast, notably low estimates of PFS were reported for sunitinib in the CABOSUN trial (NCT01835158), which only included patients with intermediate or poor risk [30]. Survival outcomes may also have been lower than expected as more than a third of patients had bone metastases and stable brain metastases [31].

Overall, outcomes in patients with PD-L1-positive tumors were similar to those reported in the overall population. Current evidence suggests that the ability of PD-L1 as a biomarker to differentiate combination treatment is limited, but there is potential to use PD-L1 expression as a marker to differentiate treatment, especially with avelumab plus axitinib, although this combination is approved for all patients regardless of PD-L1 expression. Other challenges to the use of PD-L1 as a biomarker include the availability of numerous and treatment-specific antibodies, differential expression of PD-L1 between primary RCC and metastases, remodeling of PD-L1 expression by anti-angiogenic treatment, and the need to use refined Response Evaluation Criteria In Solid Tumors (RECIST) criteria to measure the atypical response to immune checkpoint inhibitors [32]. Nevertheless, PD-L1 may have potential as a prognostic biomarker in specific subtypes of RCC, such as Xp11 translocations, where high PD-L1 expression has been associated with lower recurrence-free survival [33].

In our analysis, the majority of studies stratified patients according to MSKCC or IMDC. The efficacy and effectiveness of treatment appeared to be comparable between these two prognostic models. An analysis of 672 patients demonstrated a high level of concordance between these two prognostic models, with approximately $83 \%$ of patients stratified into the same risk group [34]. Nevertheless, differences between the two models can impact prognosis. A retrospective analysis of 176 patients treated with first-line TKIs found that significantly poorer outcomes were observed in patients with disagreement of risk category between the models [35]. Disparities may be especially pronounced between intermediate and poor risk stratification [10]. A retrospective analysis of six clinical trials found that the most common risk factors patients present with were $<1$ year from diagnosis to treatment alone, low hemoglobin alone and low hemoglobin with $<1$ year from diagnosis to treatment [36]; however, it is unclear whether certain prognostic factors are more impactful than others. Furthermore, as current prognostic models are predominantly based on data from patients treated with VEGF-targeted therapy, it may be beneficial to update these models by inclusion of data from patients treated with combination therapy.

It is becoming increasingly apparent that the intermediate risk group (one or two risk factors) is heterogeneous [23,36-39]. According to the IMDC and MSKCC models, the majority of patients present with intermediate risk, at 52 and $59 \%$ of patients, respectively [34]. Two studies included in our analysis examined outcomes in sunitinib-treated patients according to number of risk factors. In one study by Iacovelli et al., sunitinib-treated patients with one IMDC risk factor had significantly longer OS (32.9 months) compared with patients with two IMDC risk factors (20.0 months), which was validated in an independent cohort of patients [38]. A separate retrospective analysis by Rini $e t$ al., reported that median OS was longer in sunitinib-treated patients with one risk factor compared with patients with two risk factors according to both IMDC and MSKCC prognostic models [23]. Differences in clinical outcomes between patients with one versus two IMDC or MSKCC risk factors appears to predominantly impact OS, with reports of both statistically significant [36] and nonsignificant effects on PFS [23]. All available analyses that focus on outcomes according to the number of IMDC or MSKCC risk factors are based on 
patients who received sunitinib. There is a paucity of data available for other approved mRCC treatments that have examined outcomes according to the number of risk factors rather than risk group. The apparent heterogeneity of the intermediate risk group suggests that these data are important for both prognostication and interpretation of clinical trials data. Further investigation of treatment outcomes by number of risk factors is warranted.

The principal strengths of this analysis include the prespecified systematic literature review guided by PRISMA and Cochrane's dual review methodology. The results of this analysis should be interpreted with careful consideration given to the particular strengths and limitations of the included articles. No statistical adjustments were used to summarize treatment effects in our review of the available data. Our review focused on absolute outcomes of survival; an analysis of immune checkpoint inhibitors and respective treatment effects based on relative scales (hazard and odds ratios) has been previously published [40]. To fully understand the effects of a particular treatment in a given population, it is important to consider multiple measures, including the absolute measures of survival reported herein, as well as relative measures such as hazard ratios [41]. In addition, when interpreting clinical data and subgroup analyses, it is also important to consider heterogeneity of treatment effects, i.e. that a given intervention is effective for at least some of the participants. There are multiple factors that can contribute to potential treatment benefit that are not always considered when overall results are generalized [42]. In this respect, whole genomic and transcriptomic analyses may provide improved predictive/prognostic biomarkers as discussed below. Although all articles were assessed for quality and risk of bias, with the majority being of moderate-to-high quality, additional sources of bias could not be ruled out. Variation in follow-up periods between articles may impact reported survival outcomes, especially with respect to OS. Furthermore, not all studies reported results according to individual risk groups. The inclusion of articles from conference proceedings also presents a risk of bias due to the limited published data and relatively minimal external scrutiny compared with full-text articles. It should be noted that although patients with sarcomatoid histology were eligible for inclusion in this review, the majority of studies, especially RCTs, were primarily based on patients with clear cell RCC. Furthermore, the majority of articles investigated sunitinib, with relatively few articles investigating other recommended mRCC treatment options.

\section{Conclusion}

The reported efficacy and effectiveness of first-line mRCC treatment varied according to risk group, and support recently updated treatment guidelines. Risk group outcomes may be treatment-specific. Further investigation of treatment response by the number and type of risk factors may be warranted. Treatment efficacy and effectiveness appear to be consistent whether patients are stratified by MSKCC or IMDC.

\section{Future perspective}

In this analysis, we have presented collective evidence in support of treatment selection by risk categories across the two most common RCC prognostic models. These models were developed based on data from patients treated with IFN- $\alpha$ or VEGF targeted therapy $[43,44]$. As more data become available from patients treated with combination therapy, it is important that these prognostic models are re-examined and updated to ensure optimal treatment selection and outcomes. In the absence of these data, implementing easily applicable changes to exisiting prognsotic models may help improve patient outcomes. One promising approach is replacing absolute neutrophil and platelet counts with the neutrophil-to-lymphocyte ratio (NLR) and platelet-to-lymphocyte ratio (PLR). Low baseline NLR and, to a leser extent, PLR are associated with longer OS in patients with mRCC and using these ratios instead of absolute counts has been reported to improve the accuracy of the IMDC model [45,46]. Numerous other prognostic factors have been identified, such as low serum sodium [47], which could be added to exisiting models; however, while initial data are promising, many potential prognostic factors still require validation in larger, external populations before they can be incorporated into clinical practice.

The development of gene signatures and genomic biomarkers to help differentiate treatment selection has been a particular focus of recent research. As these signatures are refined and validated, we anticipate that they will form a more central part of informed treatment selection. Analysis of the JAVELIN Renal 101 trial (NCT02684006) found that patients with high expression of the JAVELIN Renal 101 gene signature had prolonged PFS when treated with avelumab plus axitinib, whereas high expression of the IMmotion 150 angiogenesis gene signature was associated with prolonged PFS in patients who received sunitinib [48]. The IMmotion 150 angiogenesis gene signature consists of previously identified genes associated with angiogenesis, which were used to define a high and low angiogenesis gene signature. A significantly higher ORR was associated with the high angiogenesis gene signature (46\%) compared with the low angiogenesis gene signature $(9 \% ; \mathrm{p}<0.001)$ in sunitinib-treated patients [49]. Treatment- 
specific responses associated with particular gene sequences most likely reflect the underlying molecular biology of the tumor. For example, tumors that were more responsive to sunitinib with a high angiogenesis gene signature, may indicate that the tumor was in a relatively early stage of development, hence inhibition of angiogenesis was more effective compared with more established tumors. Further defining the molecular characteristics of tumors may yield additional gene signatures or biomarkers to help improve treatment selection. The main challenge in implanting gene signatures into clinical practice will be the validation of these signatures in independent datasets.

Five years from the development of this review, we would expect to see an update of the prognostic models used to stratify patients. Given the growing body of evidence that the intermediate risk group is heterogenous, a refined prognostic model may include four risk groups as opposed to the current three. It is possible that genomic markers may form part of an updated prognostic model. For example, incorporating the mutational status of three genes (BAP1, PBRM1 and TP53) into the MSKCC model, improved prediction of PFS and OS in patients treated with first-line TKIs and distributed patients across four prognostic groups rather than three [50]. In addition, an analysis of 54 patients with mRCC concluded that the 34-gene signature, ClearCode34, improved patient stratification using IMDC [51]. Genomic assessment of RCC has shown that there is large heterogeneity between and within tumor types, same tumor samples as well as during specific phases of disease development [52,53]. However, some of these mutations are common and act as 'driver' mutations, such as mutation of the von Hippel-Lindau gene. Common subsequent mutations in clear cell RCC occur in PBRM1, BAP1, SETD2, $m$ TOR and PTEN [52]. These genomic alterations may lead to primary and secondary resistance to systemic treatment [53]. Identification of common genomic alterations and understanding mechanisms of resistance could have predictive significance for treatment selection. Notably, four molecular subtypes (ccrcc1-4) were identified in a global transcriptome analysis of resected tumors from patients with clear cell mRCC who received first-line sunitinib [54]. The majority of IMDC favorable-risk patients had the ccrcc 2 molecular subtype, characterized by high expression of pro-angiogenic genes. It is hypothesized that this may account for the enhanced responses to sunitinib in patients with favorable risk compared with nivolumab plus ipilimumab observed in the Checkmate 214 trial (NCT02231749) [55]. The integration of genomic markers into updated prognostic models may not only improve patient stratification, but also help guide patient management, including the optimal sequence of treatment for patients who progress on their current treatment. In the absence of updated models, it is vital that clinicians continue to routinely assess the risk status of patients as part of the treatment decision-making process.

\section{Summary points}

- The treatment of metastatic renal cell carcinoma (mRCC) has changed dramatically with the recent approval of three combination treatments: nivolumab plus ipilimumab, avelumab plus axitinib and pembrolizumab plus axitinib.

- Updated guidelines recommend that first-line treatment should be selected according to patient risk group.

- A systematic review was performed to evaluate survival and response to first-line mRCC treatments, stratified by prognostic risk.

- Of the 1256 identified articles, 40 full-length articles (16 randomized controlled trials, 24 nonrandomized controlled trials) and seven abstracts (conference proceedings) were included for analysis.

- The majority of studies stratified patients by the International Metastatic RCC Database Consortium (IMDC) alone (19 studies) or the Memorial Sloan Kettering Cancer Center (MSKCC) alone (21 studies).

- In general, therapeutic benefit appeared to be most pronounced in patients with favorable risk, followed by intermediate and poor risk.

- Combination treatments were associated with the greatest response and survival outcomes in intermediate and poor risk patients.

- Patients with favorable-risk benefit from sunitinib treatment.

- Further investigation into treatment-specific risk group outcomes is warranted and current risk criteria from prognostic models requires updating to improve patient stratification and clinical outcomes.

- Updated prognostic models may include four risk groups and may be enhanced by the inclusion of genomic markers. 
Author contributions

All authors made substantial contributions to: the conception, design, analysis and interpretation of data; drafting and critical revision of the work for important intellectual content; provided final approval of the manuscript for publication, and agreed to be accountable for all aspects of the work in ensuring that questions related to the accuracy or integrity of any part of the work are appropriately investigated and resolved.

Financial \& competing interests disclosure

$S$ Bazarbashi has received honoraria from Pfizer for serving on advisory boards, conference sponsorship, and research grants from Pfizer. A Alsharm and J Zekri have served in an advisory role for Pfizer. F Azam has received honoraria from Pfizer for serving on advisory boards and as a speaker. $\mathrm{H}$ El Ashry was an employee and shareholder of Pfizer Inc at the time of the study. The systematic literature review to support this report was sponsored by Pfizer. A Chopra of Curo provided editorial, research and writing support for the development of the systematic literature review, which was funded by Pfizer. The authors have no other relevant affiliations or financial involvement with any organization or entity with a financial interest in or financial conflict with the subject matter or materials discussed in the manuscript apart from those disclosed.

Medical writing support was provided by L Adams of Engage Scientific Solutions, and funded by Pfizer.

Data sharing statement

Upon request, and subject to certain criteria, conditions and exceptions (see https://www.pfizer.com/science/clinical-trials/trial-d ata-and-results for more information), Pfizer will provide access to individual de-identified participant data from Pfizer-sponsored global interventional clinical studies conducted for medicines, vaccines and medical devices (1) for indications that have been approved in the US and/or EU or (2) in programs that have been terminated (i.e., development for all indications has been discontinued). Pfizer will also consider requests for the protocol, data dictionary and statistical analysis plan. Data may be requested from Pfizer trials 24 months after study completion. The de-identified participant data will be made available to researchers whose proposals meet the research criteria and other conditions, and for which an exception does not apply, via a secure portal. To gain access, data requestors must enter into a data access agreement with Pfizer.

Open access

This work is licensed under the Attribution-NonCommercial-NoDerivatives 4.0 Unported License. To view a copy of this license, visit http://creativecommons.org/licenses/by-nc-nd/4.0/

\section{References}

Papers of special note have been highlighted as: $\bullet$ of interest

1. Bray F, Ferlay J, Soerjomataram I, Siegel RL, Torre LA, Jemal A. Global cancer statistics 2018: GLOBOCAN estimates of incidence and mortality worldwide for 36 cancers in 185 countries. CA Cancer J. Clin. 68(6), 394-424 (2018).

2. Dabestani S, Thorstenson A, Lindblad P, Harmenberg U, Ljungberg B, Lundstam S. Renal cell carcinoma recurrences and metastases in primary non-metastatic patients: a population-based study. World J. Urol. 34(8), 1081-1086 (2016).

3. Motzer RJ, Hutson TE, Tomczak P et al. Sunitinib versus interferon alfa in metastatic renal-cell carcinoma. N. Engl. J. Med. 356(2), 115-124 (2007).

4. Motzer RJ, Penkov K, Haanen J et al. Avelumab plus axitinib versus sunitinib for advanced renal-cell carcinoma. N. Engl. J. Med. 380(12), 1103-1115 (2019).

- Avelumab plus axitinib showed improved progression-free survival (PFS) and objective response rate (ORR) compared with sunitinib in this Phase III study of patients with metastatic renal cell carcinoma (mRCC).

5. Motzer RJ, Tannir NM, McDermott DF et al. Nivolumab plus ipilimumab versus sunitinib in advanced renal-cell carcinoma. $N$. Engl. J. Med. 378(14), 1277-1290 (2018).

- Phase III study that reported longer overall survival (OS) and higher ORR with nivolumab plus ipilimumab versus sunitinib in intermediate and poor risk mRCC patients. In favorable risk patients, PFS and ORR were higher with sunitinib versus nivolumab plus ipilimumab.

6. Rini BI, Plimack ER, Stus V et al. Pembrolizumab plus axitinib versus sunitinib for advanced renal-cell carcinoma. N. Engl. J. Med. 380(12), 1116-1127 (2019).

- Key Phase III study that demonstrated improved PFS, OS and ORR with pembrolizumab plus axitinib compared with sunitinib in patients with mRCC.

7. Escudier B, Porta C, Schmidinger M et al. Renal cell carcinoma: ESMO Clinical Practice Guidelines for diagnosis, treatment and follow-up. Ann. Oncol. 30(5), 706-720 (2019).

- Revised European Society for Medical Oncology guidelines for the treatment of RCC. 
8. National Comprehensive Cancer Network. Kidney cancer (version 2.2020) (2019). https://www.nccn.org/professionals/physician_gls/pdf/kidney.pdf

- Updated National Comprehensive Cancer Network guidelines for the treatment of RCC

9. Gore ME, Szczylik C, Porta C et al. Final results from the large sunitinib global expanded-access trial in metastatic renal cell carcinoma. Br. J. Cancer 113(1), 12-19 (2015).

10. Noe A, de Bruijn RE, Blank C, Horenblas S, Haanen J, Bex A. Comparison of pre-treatment MSKCC and IMDC prognostic risk models in patients with synchronous metastatic renal cell carcinoma treated in the era of targeted therapy. World J. Urol. 34(8), 1067-1072 (2016).

11. Higgins J, Lasserson T, Chandler J, Tovey D, Churchill R. Methodological expectations of cochrane intervention reviews (MECIR) (2016). https://methods.cochrane.org/sites/default/files/public/uploads/Cochrane\%20MECIR_Standards\%20FINAL\%20 booklet_web_version.pdf

12. Liberati A, Altman DG, Tetzlaff J et al. The PRISMA statement for reporting systematic reviews and meta-analyses of studies that evaluate health care interventions: explanation and elaboration. J. Clin. Epidemiol. 62(10), e1-e34 (2009).

13. Morrison A, Polisena J, Husereau D et al. The effect of English-language restriction on systematic review-based meta-analyses: a systematic review of empirical studies. Int. J. Technol. Assess. Health Care 28(2), 138-144 (2012).

14. Scottish Intercollegiate Guidelines Network. Search filters: randomised controlled trials (2019). www.sign.ac.uk/search-filters.html

15. National Institute for Health and Care Excellence. NICE technology appraisal guidance (2018). www.nice.org.uk/about/what-we-do/our-programmes/nice-guidance/nice-technology-appraisal-guidance

16. Wells G, Shea B, O’Connell D, Peterson J, Welch V, Losos M. The Newcastle-Ottawa Scale (NOS) for assessing the quality of nonrandomised studies in meta-analyses. (2013). http://www.ohri.ca/programs/clinical_epidemiology/oxford.asp

17. Savard M-F, Wells JC, Graham J et al. Real-world assessment of clinical outcomes among first-line (1L) sunitinib (SUN) patients (pts) with metastatic renal cell carcinoma (mRCC) by the international mRCC database consortium (IMDC) risk group. J. Clin. Oncol. 37(Suppl. 7), 610 (2019).

18. Shinohara N, Nonomura K, Abe $\mathrm{T}$ et al. A new prognostic classification for overall survival in Asian patients with previously untreated metastatic renal cell carcinoma. Cancer Sci. 103(9), 1695-1700 (2012).

19. McDermott DF, Cheng SC, Signoretti S et al. The high-dose aldesleukin "select" trial: a trial to prospectively validate predictive models of response to treatment in patients with metastatic renal cell carcinoma. Clin. Cancer Res. 21(3), 561-568 (2015).

20. Choueiri TK, Motzer RJ, Campbell MT et al. Subgroup analysis from JAVELIN Renal 101: outcomes for avelumab plus axitinib (A + Ax) versus sunitinib (S) in advanced renal cell carcinoma (aRCC). J. Clin. Oncol. 37(Suppl. 7), 544 (2019).

21. Kubackova K, Melichar B, Bortlicek Z et al. Comparison of two prognostic models in patients with metastatic renal cancer treated with sunitinib: a retrospective, registry-based study. Target. Oncol. 10(4), 557-563 (2015).

22. Lolli C, Basso U, Derosa L et al. Systemic immune-inflammation index predicts the clinical outcome in patients with metastatic renal cell cancer treated with sunitinib. Oncotarget 7(34), 54564-54571 (2016).

23. Rini BI, Hutson TE, Figlin RA et al. Sunitinib in patients with metastatic renal cell carcinoma: clinical outcome according to International Metastatic Renal Cell Carcinoma Database Consortium Risk Group. Clin. Genitourin. Cancer 16(4), 298-304 (2018).

- Retrospective analysis of sunitinib-treated patients that showed different OS responses in patients with one or two risk factors, suggesting the intermediate risk group is heterogeneous.

24. Moran M, Nickens D, Adcock K, Bennetts M, Charnley N, Fife K. Augmenting the randomized controlled trial with real-world data to aid clinical decision making in metastatic renal cell carcinoma: a systematic review and meta-analysis. Future Oncol. 15(34), 3987-4001 (2019).

25. De Giorgi U, Rihawi $\mathrm{K}$, Aieta $\mathrm{M}$ et al. Lymphopenia and clinical outcome of elderly patients treated with sunitinib for metastatic renal cell cancer. J. Geriatr. Oncol. 5(2), 156-163 (2014).

26. Mitchell AP, Harrison MR, Walker MS, George DJ, Abernethy AP, Hirsch BR. Clinical trial participants with metastatic renal cell carcinoma differ from patients treated in real-world practice. J. Oncol. Pract. 11(6), 491-497 (2015).

27. Heng DY, Choueiri TK, Rini BI et al. Outcomes of patients with metastatic renal cell carcinoma that do not meet eligibility criteria for clinical trials. Ann. Oncol. 25(1), 149-154 (2014).

28. Marschner N, Staehler M, Muller L et al. Survival of patients with advanced or metastatic renal cell carcinoma in routine practice differs from that in clinical trials-analyses from the German Clinical RCC Registry. Clin. Genitourin. Cancer 15(2), e209-e215 (2017).

29. Nieder C, Syed MA, Dalhaug A, Pawinski A, Norum J. Eligibility for Phase III clinical trials of systemic therapy in real-world patients with metastatic renal cell cancer managed in a rural region. Med. Oncol. 34(9), 149 (2017).

30. Choueiri TK, Hessel C, Halabi $S$ et al. Cabozantinib versus sunitinib as initial therapy for metastatic renal cell carcinoma of intermediate or poor risk (Alliance A031203 CABOSUN randomised trial): progression-free survival by independent review and overall survival update. Eur. J. Cancer 94, 115-125 (2018). 
31. Choueiri TK, Halabi S, Sanford BL et al. Cabozantinib versus sunitinib as initial targeted therapy for patients with metastatic renal cell carcinoma of poor or intermediate risk: the Alliance A031203 CABOSUN Trial. J. Clin. Oncol. 35(6), 591-597 (2017).

32. Kammerer-Jacquet SF, Deleuze A, Saout J et al. Targeting the PD-1/PD-L1 pathway in renal cell carcinoma. Int. J. Mol. Sci. 20(7), (2019).

33. Lee HJ, Shin DH, Lee YJ et al. PD-L1 expression and infiltration by CD4+ and FOXP3+ T cells are increased in Xp11 translocation renal cell carcinoma and indicate poor prognosis. Histopathology doi:10.1111/his.14047 (2019) (Epub ahead of print).

34. Heng DY, Xie W, Regan MM et al. External validation and comparison with other models of the International Metastatic Renal-Cell Carcinoma Database Consortium prognostic model: a population-based study. Lancet Oncol. 14(2), 141-148 (2013).

- Validation of the International Metastatic RCC Database Consortium prognostic model and comparison with other prognostic models, reporting high concordance between International Metastatic RCC Database Consortium and Memorial Sloan Kettering Cancer Center models.

35. Okita K, Hatakeyama S, Tanaka T et al. Impact of disagreement between two risk group models on prognosis in patients with metastatic renal-cell carcinoma. Clin. Genitourin. Cancer 17(3), e440-e446 (2019).

36. Sella A, Michaelson MD, Matczak E, Simantov R, Lin X, Figlin RA. Heterogeneity of patients with intermediate-prognosis metastatic renal cell carcinoma treated with sunitinib. Clin. Genitourin. Cancer 15(2), 291-299 e291 (2017).

37. Fay AP, Xie WL, Lee JL et al. Characteristics of long-term and short-term survivors of metastatic renal cell carcinoma treated with targeted therapies: results from the International mRCC Database Consortium. Clin. Genitourin. Cancer 13(2), 150-155 (2015).

38. Iacovelli R, De Giorgi U, Galli L et al. Is It possible to improve prognostic classification in patients affected by metastatic renal cell carcinoma with an intermediate or poor prognosis? Clin. Genitourin. Cancer 16(5), 355-359 (2018).

39. Savard MF, Wells JC, Graham J et al. Real-world assessment of clinical outcomes among first-line sunitinib patients with clear cell metastatic renal cell carcinoma (mRCC) by the International mRCC Database Consortium Risk Group. Oncologist 25(5), 422-430 (2020).

40. Adashek JJ, Genovese G, Tannir NM, Msaouel P. Recent advancements in the treatment of metastatic clear cell renal cell carcinoma: a review of the evidence using second-generation p-values. Cancer Treat Res. Commun. 23, 100166 (2020).

41. Sashegyi A, Ferry D. On the Interpretation of the Hazard Ratio and Communication of Survival Benefit. Oncologist 22(4), 484-486 (2017).

42. Kent DM, Steyerberg E, van Klaveren D. Personalized evidence based medicine: predictive approaches to heterogeneous treatment effects. BMJ 363, k4245 (2018).

43. Heng DY, Chi KN, Murray N et al. A population-based study evaluating the impact of sunitinib on overall survival in the treatment of patients with metastatic renal cell cancer. Cancer 115(4), 776-783 (2009).

44. Motzer RJ, Bacik J, Murphy BA, Russo P, Mazumdar M. Interferon-alfa as a comparative treatment for clinical trials of new therapies against advanced renal cell carcinoma. J. Clin. Oncol. 20(1), 289-296 (2002).

45. Chrom P, Stec R, Bodnar L, Szczylik C. Incorporating neutrophil-to-lymphocyte ratio and platelet-to-lymphocyte ratio in place of neutrophil count and platelet count improves prognostic accuracy of the International Metastatic Renal Cell Carcinoma Database Consortium Model. Cancer Res. Treat. 50(1), 103-110 (2018).

46. Tanaka N, Mizuno R, Yasumizu Y et al. Prognostic value of neutrophil-to-lymphocyte ratio in patients with metastatic renal cell carcinoma treated with first-line and subsequent second-line targeted therapy: a proposal of the modified-IMDC risk model. Urol. Oncol. 35(2), 39.e19-39.e28 (2017).

47. Schutz FA, Xie W, Donskov F et al. The impact of low serum sodium on treatment outcome of targeted therapy in metastatic renal cell carcinoma: results from the International Metastatic Renal Cell Cancer Database Consortium. Eur. Urol. 65(4), 723-730 (2014).

48. Choueiri TK, Albiges L, Haanen JBAG et al. Biomarker analyses from JAVELIN Renal 101: avelumab + axitinib (A + Ax) versus sunitinib (S) in advanced renal cell carcinoma (aRCC). J. Clin. Oncol. 37(Suppl. 15), 101-101 (2019).

49. McDermott DF, Huseni MA, Atkins MB et al. Clinical activity and molecular correlates of response to atezolizumab alone or in combination with bevacizumab versus sunitinib in renal cell carcinoma. Nat. Med. 24(6), 749-757 (2018).

50. Voss MH, Reising A, Cheng Y et al. Genomically annotated risk model for advanced renal-cell carcinoma: a retrospective cohort study. Lancet Oncol. 19(12), 1688-1698 (2018).

51. de Velasco G, Culhane AC, Fay AP et al. Molecular subtypes improve prognostic value of International Metastatic Renal Cell Carcinoma Database Consortium Prognostic Model. Oncologist 22(3), 286-292 (2017).

52. Massari F, Nunno VD, Mollica $\mathrm{V}$ et al. Immunotherapy in renal cell carcinoma from poverty to the spoiled of choice. Immunotherapy 11(17), 1507-1521 (2019).

53. Mollica V, Di Nunno V, Gatto L et al. Resistance to systemic agents in renal cell carcinoma predict and overcome genomic strategies adopted by tumor. Cancers (Basel) 11(6), (2019).

54. Beuselinck B, Job S, Becht E et al. Molecular subtypes of clear cell renal cell carcinoma are associated with sunitinib response in the metastatic setting. Clin. Cancer Res. 21(6), 1329-1339 (2015). 
55. Beuselinck B, Verbiest ATL, Couchy G et al. Tumor molecular characteristics in patients (pts) with international metastatic renal cell carcinoma database consortium (IMDC) good (G) and intermediate/poor (I/P) risk. Ann. Oncol. 29(Suppl. 8), viii303-viii331 (2018).

56. Cella D, Grunwald V, Escudier B et al. Patient-reported outcomes of patients with advanced renal cell carcinoma treated with nivolumab plus ipilimumab versus sunitinib (CheckMate 214): a randomised, Phase III trial. Lancet Oncol. 20(2), 297-310 (2019).

57. Donskov F, Jensen NV, Smidt-Hansen T, Brondum L, Geertsen P. A randomized Phase II trial of interleukin-2 and interferon-alpha plus bevacizumab versus interleukin-2 and interferon-alpha in metastatic renal-cell carcinoma (mRCC): results from the Danish Renal Cancer Group (DaRenCa) study-1. Acta Oncol. 57(5), 589-594 (2018).

58. Eichelberg C, Vervenne WL, De Santis M et al. SWITCH: a randomised, sequential, open-label study to evaluate the efficacy and safety of sorafenib-sunitinib versus sunitinib-sorafenib in the treatment of metastatic renal cell cancer. Eur. Urol. 68(5), 837-847 (2015).

59. Escudier B, Pluzanska A, Koralewski $P$ et al. Bevacizumab plus interferon alfa-2a for treatment of metastatic renal cell carcinoma: a randomised, double-blind Phase III trial. Lancet 370(9605), 2103-2111 (2007).

60. Escudier B, Bellmunt J, Negrier $S$ et al. Phase III trial of bevacizumab plus interferon alfa-2a in patients with metastatic renal cell carcinoma (AVOREN): final analysis of overall survival. J. Clin. Oncol. 28(13), 2144-2150 (2010).

61. Hudes G, Carducci M, Tomczak P et al. Temsirolimus, interferon alfa, or both for advanced renal-cell carcinoma. N. Engl. J. Med. 356(22), 2271-2281 (2007).

62. Hutson TE, Lesovoy V, Al-Shukri S et al. Axitinib versus sorafenib as first-line therapy in patients with metastatic renal-cell carcinoma: a randomised open-label Phase III trial. Lancet Oncol. 14(13), 1287-1294 (2013).

63. Mejean A, Ravaud A, Thezenas S et al. Sunitinib alone or after nephrectomy in metastatic renal-cell carcinoma. N. Engl. J. Med. 379(5), 417-427 (2018).

64. Motzer RJ, Hutson TE, Tomczak P et al. Overall survival and updated results for sunitinib compared with interferon alfa in patients with metastatic renal cell carcinoma. J. Clin. Oncol. 27(22), 3584-3590 (2009).

65. Motzer RJ, Nosov D, Eisen T et al. Tivozanib versus sorafenib as initial targeted therapy for patients with metastatic renal cell carcinoma: results from a Phase III trial. J. Clin. Oncol. 31(30), 3791-3799 (2013).

66. Rini BI, Halabi S, Rosenberg JE et al. Bevacizumab plus interferon alfa compared with interferon alfa monotherapy in patients with metastatic renal cell carcinoma: CALGB 90206. J. Clin. Oncol. 26(33), 5422-5428 (2008).

67. Tannir NM, Frontera OA, Hammers HJ et al. Thirty-month follow-up of the phase III CheckMate 214 trial of first-line nivolumab + ipilimumab (N+ I) or sunitinib (S) in patients (pts) with advanced renal cell carcinoma (aRCC). J. Clin. Oncol. 37(Suppl. 7), 547 (2019).

68. Boegemann M, Hubbe M, Thomaidou D et al. Sunitinib treatment modification in first-line metastatic renal cell carcinoma: analysis of the STAR-TOR registry. Anticancer Res. 38(11), 6413-6422 (2018).

69. Bozkurt O, Hacibekiroglu I, Kaplan MA et al. Is late recurrence a predictive clinical marker for better sunitinib response in metastatic renal cell carcinoma patients? Clin. Genitourin. Cancer 13(6), 548-554 (2015).

70. Coelho RC, Reinert T, Campos F et al. Sunitinib treatment in patients with advanced renal cell cancer: the Brazilian National Cancer Institute (INCA) experience. Int. Braz J. Urol. 42(4), 694-703 (2016).

71. De Giorgi U, Scarpi E, Sacco C et al. Standard vs adapted sunitinib regimen in elderly patients with metastatic renal cell cancer: results from a large retrospective analysis. Clin. Genitourin. Cancer 12(3), 182-189 (2014).

72. Harshman LC, Kroeger N, Rha SY et al. First-line Mammalian target of rapamycin inhibition in metastatic renal cell carcinoma: an analysis of practice patterns from the International Metastatic Renal Cell Carcinoma Database Consortium. Clin. Genitourin. Cancer 12(5), 335-340 (2014).

73. Joshi A, Ramaswamy A, Noronha $\mathrm{V}$ et al. Efficacy and safety of sorafenib in advanced renal cell cancer and validation of Heng criteria. Indian J. Cancer 53(3), 423-428 (2016).

74. Lalani AA, Li H, Heng DYC et al. First-line sunitinib or pazopanib in metastatic renal cell carcinoma: the Canadian experience. Can. Urol. Assoc. J. 11(3-4), 112-117 (2017).

75. Omae K, Kondo $\mathrm{T}$, Kennoki $\mathrm{T}$ et al. Efficacy and safety of sorafenib for treatment of Japanese metastatic renal cell carcinoma patients undergoing hemodialysis. Int. J. Clin. Oncol. 21(1), 126-132 (2016).

76. Perez-Valderrama B, Arranz Arija JA, Rodriguez Sanchez A et al. Validation of the International Metastatic Renal-Cell Carcinoma Database Consortium (IMDC) prognostic model for first-line pazopanib in metastatic renal carcinoma: the Spanish Oncologic Genitourinary Group (SOGUG) SPAZO study. Ann. Oncol. 27(4), 706-711 (2016).

77. Santoni M, Conti A, Porta C et al. Sunitinib, pazopanib or sorafenib for the treatment of patients with late relapsing metastatic renal cell carcinoma. J. Urol. 193(1), 41-47 (2015).

78. Sastre-Heres AJ, Calero MA, Ruiz-Sanchez D et al. Study of the effectiveness of first-line treatment in renal cell carcinoma. Mol. Clin. Oncol. 2(6), 1167-1171 (2014).

79. Schmidinger M, Porta C, Oudard S et al. Real-world experience with sunitinib treatment in patients with metastatic renal cell carcinoma: clinical outcome according to risk score. J. Clin. Oncol. 37(Suppl. 7), 606 (2019). 
80. Stenehjem DD, Toole M, Merriman J et al. Extension of overall survival beyond objective responses in patients with metastatic renal cell carcinoma treated with high-dose interleukin-2. Cancer Immunol. Immunother. 65(8), 941-949 (2016).

81. Warren M, Venner PM, North S et al. A population-based study examining the effect of tyrosine kinase inhibitors on survival in metastatic renal cell carcinoma in Alberta and the role of nephrectomy prior to treatment. Can. Urol. Assoc. J. 3(4), 281-289 (2009).

82. Yildiz I, Sen F, Kilic L et al. Prognostic factors associated with the response to sunitinib in patients with metastatic renal cell carcinoma. Curr. Oncol. 20(6), e546-e553 (2013).

83. Zhang X, Sun G, Zhao J et al. Improved long-term clinical outcomes and safety profile of sunitinib dosing schedule with $4 / 2$ switched to $2 / 1$ in patients with metastatic renal cell carcinoma. J. Cancer 9(18), 3303-3310 (2018).

84. McDermott DF, Lee JL, Szczylik C et al. Pembrolizumab monotherapy as first-line therapy in advanced clear cell renal cell carcinoma (accRCC): results from cohort A of KEYNOTE-427. J. Clin. Oncol. 36(Suppl. 15), 4500 (2018).

85. Melichar B, Bracarda S, Matveev V et al. A multinational Phase II trial of bevacizumab with low-dose interferon-alpha2a as first-line treatment of metastatic renal cell carcinoma: BEVLiN. Ann. Oncol. 24(9), 2396-2402 (2013).

86. Zurita AJ, Ross JA, Devine CE et al. A randomized Phase II trial of pazopanib (PAZ) vs. temsirolimus (TEM) in patients (pts) with advanced clear-cell renal cell carcinoma (accRCC) with intermediate or poor-risk disease (the TemPa trial). J. Clin. Oncol. 36(Suppl. 15), 4563 (2018). 